\title{
Methylation pattern in the promoter region of interleukin $1-\beta$ gene in animal models of mesial temporal lobe epilepsy induced by pilocarpine injection
}

Larissa Carvalho (IC), Alexandre H.B. Mattos(PQ), Danyella B. Doguini(PQ), André S. Vieira(PQ), Iscia Lopes-Cendes (PQ).

\author{
Department of Medical Genetics, University of Campinas -UNICAMP and The Brazilian Institute of Neuroscience and \\ Neurotechnology (BRAINN), Campinas, SP, Brazil
}

\begin{abstract}
The aim of this study is to determine the methylation pattern in the promoter region of the interleukin 1- $\beta$ gene in hippocampal tissue obtained from animal models of mesial temporal lobe epilepsy induced by pilocarpine injection and compare this with the methylation pattern found in tissue of control animals
\end{abstract}

Key words: epilepsy, inflammation, methylation.

\section{Introduction}

There is a growing number of evidence suggesting an association between inflammation and epilepsy (1). The role of epigenetics as a potential regulator of genes associated with epilepsy is also gaining attention (2). The aim of this project is to evaluate the methylation pattern in the promoter region of the interleukin $1-\beta$ gene in hippocampal tissue obtained from animal models of mesial temporal lobe epilepsy induced by pilocarpine injection and compare this with the methylation pattern found in tissue of control animals.

\section{Results and Discussion}

Tissue from 6 animals, male Wistar rats, was used in this project. Three of these animals were injected with pilocarpine for the induction of seizures, status epilepticus and three animals used as control group. After two weeks of the pilocarpine injection, brains were cut in the cryostat and the hippocampus was removed. Genomic DNA was extracted with the proteinase $\mathrm{K}$ protocol. The methylation pattern will be identified by the bissulfite conversion with MethylMiner Methylated DNA Enrichment Kit. Currently, we are undertaken the bisulfite experiments in order to obtain the final results.

\section{Conclusions}

I After completion of these project and subsequent studies we hope to obtain result which should shed some light into the mechanisms underlying mesial temporal lobe epilepsy.

\section{Acknowledgement}

This Project was supported by CEPID-BRAINN FAPESP, São Paulo, Brazil and PIBIQ-CNPq

\footnotetext{
Vezzani A, French J, Bartfai T, Baram TZ. The role of inflammation in epilepsy. Nat Rev Neurol. 2011;7(1):31-40

${ }^{2}$ Lubin FD. Epileptogenesis: can the science of epigenetics give us answers? Epilepsy Curr. 2012;12(3):105-10.
} 